\title{
Membrane Activity and Channel Formation of the Adenylate Cyclase Toxin (CyaA) of Bordetella pertussis in Lipid Bilayer Membranes
}

\author{
Oliver Knapp ${ }^{1, *}$ and Roland Benz ${ }^{2, *(1)}$ \\ 1 Department of Life Sciences and Chemistry, Jacobs University, Campus Ring 1, 28759 Bremen, Germany \\ 2 Rudolf-Virchow-Center, University of Würzburg, Versbacher Str. 9, 97078 Würzburg, Germany \\ * Correspondence: knapp@clin-sol.com (O.K.); R.Benz@jacobs-university.de (R.B.)
}

Received: 27 January 2020; Accepted: 22 February 2020; Published: 10 March 2020

\begin{abstract}
The Gram-negative bacterium Bordetella pertussis is the cause of whooping cough. One of its pathogenicity factors is the adenylate cyclase toxin (CyaA) secreted by a Type I export system. The 1706 amino acid long CyaA $(177 \mathrm{kDa})$ belongs to the continuously increasing family of repeat in toxin (RTX) toxins because it contains in its C-terminal half a high number of nine-residue tandem repeats. The protein exhibits cytotoxic and hemolytic activities that target primarily myeloid phagocytic cells expressing the $\alpha \mathrm{M} \beta 2$ integrin receptor (CD11b/CD18). CyaA represents an exception among RTX cytolysins because the first 400 amino acids from its $\mathrm{N}$-terminal end possess a calmodulin-activated adenylate cyclase (AC) activity. The entry of the AC into target cells is not dependent on the receptor-mediated endocytosis pathway and penetrates directly across the cytoplasmic membrane of a variety of epithelial and immune effector cells. The hemolytic activity of CyaA is rather low, which may have to do with its rather low induced permeability change of target cells and its low conductance in lipid bilayer membranes. CyaA forms highly cation-selective channels in lipid bilayers that show a strong dependence on aqueous $\mathrm{pH}$. The pore-forming activity of CyaA but not its single channel conductance is highly dependent on $\mathrm{Ca}^{2+}$ concentration with a half saturation constant of about 2 to $4 \mathrm{mM}$.
\end{abstract}

Keywords: pore formation; adenylate cyclase toxin; CyaA; Bordetella pertussis; membrane interaction; lipid bilayer

Key Contribution: This review focuses on the ability of the adenylate cyclase toxin (CyaA) of Bordetella pertussis to form cation selective transient ion-permeable channels on artificial and target cell membranes. The detailed steps of this process will be discussed and the latest results regarding this toxin/membrane interaction will be taken into consideration.

\section{Introduction}

Whooping cough is a highly transmissive disease of the human respiratory tract caused by the Gram-negative bacterium Bordetella pertussis. The adenylate cyclase toxin (CyaA) is together with pertussis toxin one of the main secreted virulence factors of this pathogen, besides other factors such as filamentous hemagglutinin, pertactin, fimbria, and tracheal cytotoxin [1]. Adenylate cyclase toxins with minor differences in the calcium-binding domain are also produced by the closely related species Bordetella parapertussis, Bordetella avium, and Bordetella bronchiseptica [2-4]. Differences between the toxins of different Bordetella species are mainly in the calcium-binding domain. CyaA is an essential factor in the early stage of bacterial colonization of the respiratory tract $[5,6]$. It enables the bacteria to escape the host immune system by primarily targeting myeloid lineage cells expressing the $\alpha_{M} \beta_{2}$ 
integrin receptor $(\mathrm{CD} 11 \mathrm{~b} / \mathrm{CD} 18)$ such as macrophages and neutrophils. These cells are the main cellular targets for CyaA [7-12]. CyaA differs from other repeat in toxin (RTX) toxins through its assembly and function as the $177 \mathrm{kDa}$ protein exhibits cytotoxic and hemolytic activities (Figure 1). The first $364 \mathrm{~N}$-terminal amino acids constitute an adenylate cyclase (AC) domain, which is translocated through a more or less unknown mechanism across the cytoplasmic membrane into the host cell (Figure 1). Following activation by the intracellular calmodulin (CaM) together with calcium leads to the uncontrolled formation of supraphysiological cyclic adenosine monophosphate (cAMP) levels from ATP, leading to the interruption of several important cellular functions [7,13]. As a result, the microbicidal capacities of the intoxicated cells are debilitated by increased concentration of cAMP followed by cAMP-mediated activations of protein kinase A (PKA) and the exchange factor directly activated by cAMP 1 (EPAC1) [2,12,13]. The AC domain shows some similarities to the adenylate cyclases found in Bacillus anthracis (edema factor) and in Pseudomonas aeruginosa (ExoY). The sequence similarities and structural isolation of these bacterial adenylate cyclases may hypothesize that the bifunctional CyaA of B. pertussis developed by the fusion of an adenylate cyclase and RTX-toxin gene [14].

The C-terminal fragment of CyaA with 1332 residues functions as a hemolysin and is able to form small cation selective channels in lipid bilayers (Figure 1) [15-18]. Thus, the hemolysin part of CyaA contains enough information for cell targeting and pore formation. This part itself is composed of several distinct domains with different functions. The translocation of the AC domain across host plasma membranes is linked to the translocation region, spanning residues 365-500, and is followed by a hydrophobic domain, which is involved in pore formation. It harbors several hydrophobic segments between residues 500 and 700 with potentially amphiphilic and hydrophobic $\alpha$-helical structures [15-22]. This region accounts for membrane insertion and shows some similarities to the pore-forming region of other RTX-toxins, e.g., the Escherichia coli $\alpha$-hemolysin HlyA [5,23].

The acylation region spans from residue 750 to 1000 and contains the two main acylation sites at lysines K860 and K983 [24-29]. Hackett et al. [24] showed that CyaA is post-translationally modified by palmitoylation on Lys 983 (Figure 1). Later on, it was found that the recombinant CyaA toxin produced in E. coli K-12 was also palmitoylated at K860 in the presence of the CyaC protein, which is an acyl-translational enzyme encoded by cyaC of the adenylate cyclase operon [25-29]. Through the enzyme action of $\mathrm{CyaC}$, palmitoyl residues are covalently attached to the $\varepsilon$-amino group of one or both of the two lysine residues at positions 860 and 983, which correspond to highly conserved residues among RTX toxins [25,28,29]. Acylation is essential for tight binding and interaction with its target cell receptors as well as for other toxin activities such as the modulation of toxin oligomerization [30,31]. However, acylation does not seem to be highly important for pore formation, as the nonacylated CyaA precursor toxin also forms pores-with a reduced frequency-in planar lipid bilayers and naked liposome membranes with similar properties as the pores formed by acylated toxin [16,25].

The next domain between residues 913 and 1612 contains about 45 glycine and aspartate-rich nonapeptide tandem repeats of the form of the type G-G-X-G-(N/D)-D-X-(L/I/F)-X (where X represents any amino acid) that form calcium-binding sites. These repeats are typical for RTX toxins (see Figure 1) and are involved in receptor binding [32-37]. The region comprised by residues 1166-1281 within this glycine-rich repeat is required for binding to the $\alpha \mathrm{M} \beta 2$ integrin receptor [38-40] (Figure 1). 


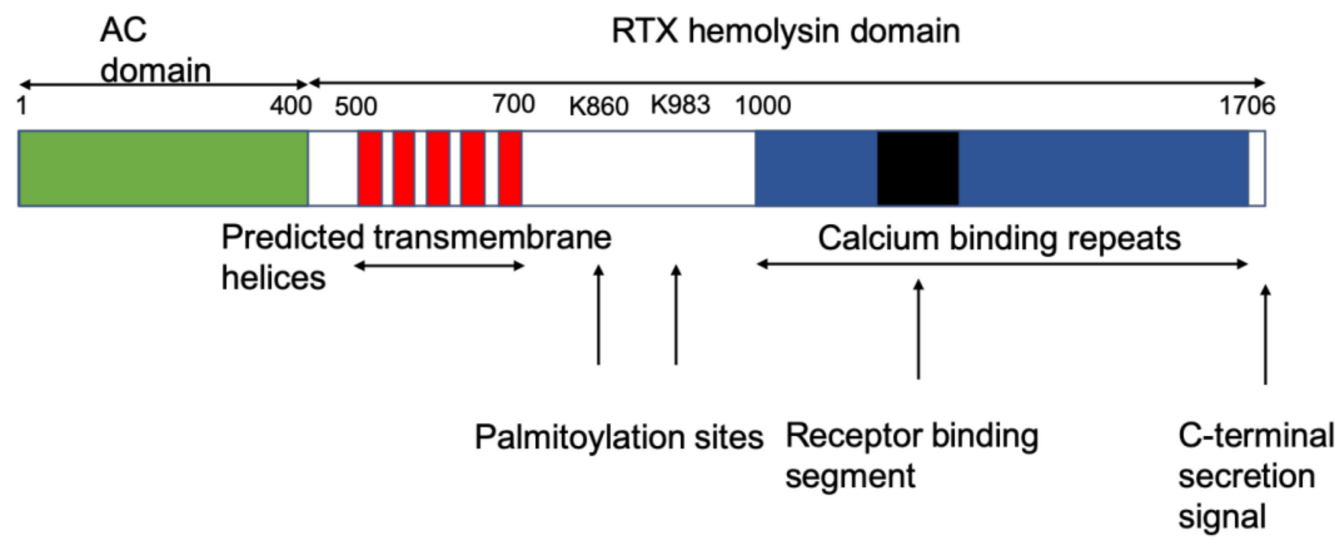

Figure 1. Schematic representation of the different domains of cyclase toxin (CyaA) of Bordetella pertussis.

Each repeat binds a single calcium ion with a binding constant between 0.5 and $0.8 \mathrm{mM}$ [41]. CyaA has about 45 of these binding sites of low affinity besides a few high-affinity binding sites, which could not be localized in CyaA [41]. Circular dichroism spectroscopy analysis revealed that calcium binding is associated with a conformational change of CyaA involving an important increase in the content of alpha-helical structures [42]. Other studies showed that calcium binding induces the formation of parallel $\beta$-roll motifs, where $\beta$-strands of two parallel sheets are connected by calcium binding. This results in the formation of a right-handed spiral within the C-terminal domain, which seems to be necessary for cell intoxication [33,34,41,42].

The last about 50 to 60 amino acids from the C-terminal end of CyaA (see Figure 1) represent the export signal because it is actively secreted from B. pertussis by a specific type I transport system [43,44]. It consists of the products of the genes $c y a B$ and $c y a D$, which are homologues of the proteins involved in E. coli hemolysin export machinery [43-45]. These genes are part of the operon cyaCABDE (in transcriptional order) [43], which contains also the gene $c y a E$ of an outer membrane protein with a function similar to the outer membrane protein TolC of E. coli $[46,47]$. The activated soluble protein-the main part remains bound to the outer membrane of the bacteria and stays inactive [48] -interacts then with the surface of the target cells. Recent results showed that the RTX toxins CyaA, HlyA, and LtxA exhibit a weak lectin activity and interact with the N-linked oligosaccharides of their $\beta 2$ integrin receptors [40]. This raises the possibility that the initial unsaturable binding of RTX cytotoxins to various cells might occur through the recognition of glycosylated membrane components such as glycoproteins and gangliosides.

\section{Membrane Interaction of CyaA: Membrane Binding, Adenylate Cyclase (AC) Translocation, and Pore Formation}

The interaction of CyaA with target cell membranes starts with the reversible adsorption of the toxin by the membrane via electrostatic interactions [18,49] followed by an irreversible membrane insertion. Once CyaA has inserted into the cell membrane, it suffers an irreversible conformational change after which it cannot be recovered from the membrane without the use of detergents [41]. Studies with the isolated calcium-binding domain of the HlyA toxin of E. coli revealed that this part of the protein might adsorb on the membrane in the early stages of HlyA-membrane interaction [50].

After membrane binding and insertion, the AC penetrates into the host cell cytosol were the $\mathrm{N}$-terminal AC domain of CyaA binds intracellular calmodulin and starts with the calmodulindependent cAMP production $[7,13]$. Through this specific enzymatic activity, cAMP is increased approximately 10,000-fold [7,51] and the subsequent bactericidal functions of phagocytes, e.g., phagocytosis and a decrease of chemotactic and oxidative burst capacities, are significantly blocked [52-54]. Moreover, the toxin can induce apoptosis in macrophages $[10,11]$ by a mechanism that involves the disruption of the mitochondrial membrane potential [55]. Veneziano et al. demonstrated 
that CyaA does not require any specific eukaryotic components apart from calmodulin to translocate its catalytic domain across a membrane [49]. The crystal structure of the AC domain of CyaA was recently solved in complex with the C-terminal fragment of calmodulin [56].

Unlike most other enzymatically active toxins, the entry of this part of the molecule is not dependent on the receptor-mediated endocytosis, and it has been shown in several different studies that the adenylate cyclase penetrates the target cell directly across the cell membrane of a variety of different cell types [57-61]. Fiser et al. showed that this unique translocation of the AC domain of CyaA also causes a novel type of membrane path for $\mathrm{Ca}^{2+}$ influx into monocytic cells [62]. This mechanism is independent of the pore formation and enzymatic activity of CyaA or the release of $\mathrm{Ca}^{2+}$ from intracellular stores [62]. The unique calcium influx pathway induces the cleavage of talin by calpain and enables the mobilization of the CyaA-CD11b/CD18 complex into lipid rafts. Lipid raft environments enriched in cholesterol appear to support the translocation of the enzymatic domain across the host cell membrane [63]. Veneziano et al. demonstrated that CyaA can be translocated across tethered lipid bilayers [49]. The translocation of the catalytic domain seems to be driven in part by the electrical field across the membrane in a calcium-dependent manner [49]. The translocation region is hereby of crucial interest, since arginine residues from the segment 454-484 within this region are involved in membrane interaction, folding, and the permeabilization of CyaA and its enzymatic domain [64]. Voegele et al. propose that this region induces a local destabilization of the membrane, thereby decreasing the energy required to translocate the catalytic domain across the plasma membrane [64].

Several groups have shown that antigens "inserted and hidden" within the amino acid sequence of the AC domain can be successfully delivered to the major histocompatibility complex-I (MHC I) complex $[38,65]$. Therefore, interest in CyaA increased significantly, and it is thought that it could be useful for the development of new vaccinations against different viruses or cancer. Another enzymatic activity was recently assigned to CyaA by González-Bullón et al., who reported that CyaA exhibits a phospholipase A activity that could destabilize the membrane to facilitate the membrane translocation of the AC domain [66]. However, others could not verify this claim. Bumba et al. and Voegele et al. could not detect any phospholipase A activity associated with the CyaA polypeptide [67,68]. It was shown that the two putative conserved phospholipase A catalytic residues Ser606 and Asp1079 are not involved in the process of membrane translocation of the AC domain of CyaA across target membranes [67]. However, González-Bullón et al. reproduced and corroborated their first observations of the CyaA-PLA activity and of the involvement of Ser606 as a catalytic site for CyaA PLA activity and its involvement in AC translocation [69].

Furthermore, the hydrophobic domain of the N-terminal part of CyaA is able to form small cation-selective transmembrane channels of a defined size and a short pore lifetime of a few seconds (Figure 2d) [16,17,69-71], and it also causes osmotic cell lysis [15]. Dose-response analyses indicated that the lytic activity on target cells is a highly cooperative function of toxin concentration (Hill number $\geq 3$ ) and slow kinetics (lag time of $>1 \mathrm{~h}$ ), suggesting that oligomerization was involved in RTX toxin pore formation [17,71-75]. Moreover, in vitro complementation experiments with pairs of individually inactive deletion variants allowed restoring, at least in part, the hemolytic and cytotoxic activities, suggesting that two or more toxin molecules associate to form a pore [76,77]. However, Gray et al. observed that CyaA induced a rapid increase in $\mathrm{K}^{+}$-efflux from sheep erythrocytes and Jurkat cells [74]. The dependence of this process on toxin concentration together with the analysis of the time course suggested that $\mathrm{CyaA}$ monomers are sufficient to induce such a $\mathrm{K}^{+}$-efflux. The author agreed that pore formation requires oligomerization and state that the $\mathrm{AC}$ translocation-related $\mathrm{K}^{+}$-efflux is separate and distinct from the structure required for intoxication [74]. 

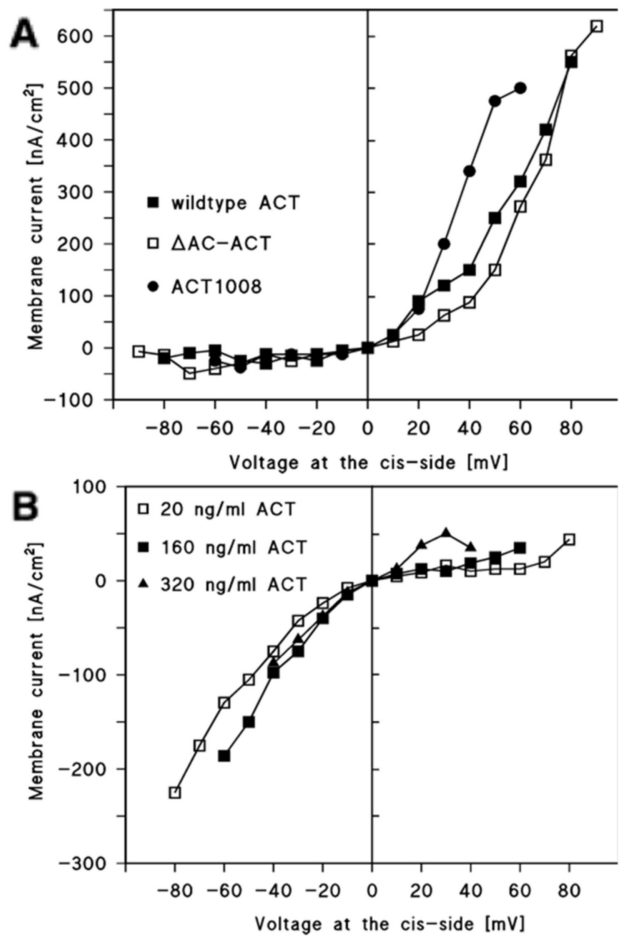
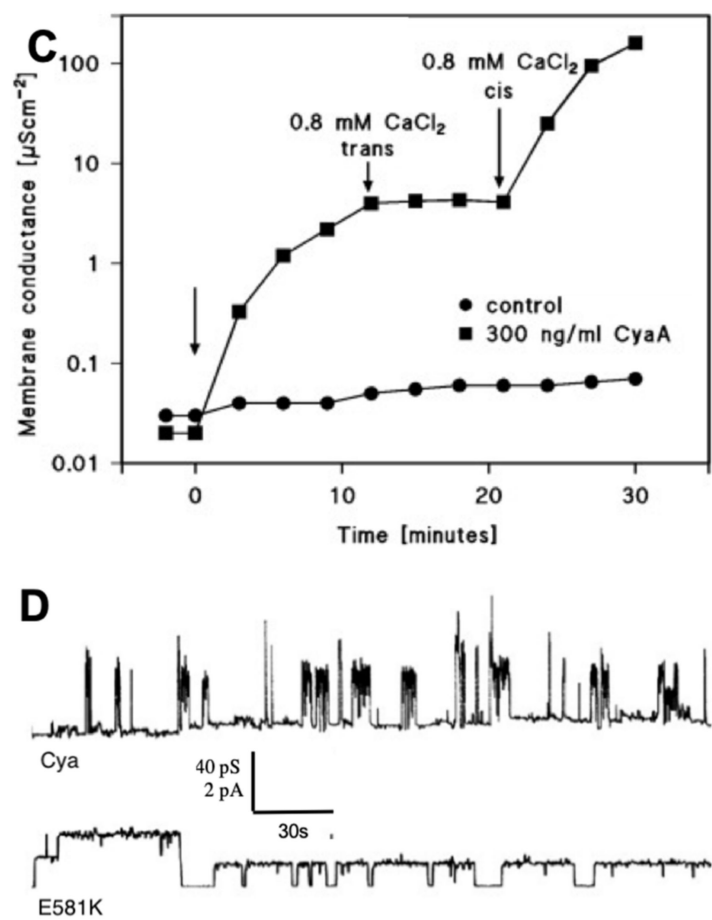

Figure 2. (a) Current-voltage relationships of cyclase toxin (CyaA) pores initiated by positive potential $(+50 \mathrm{mV})$ applied to the cis side. The membranes were formed from asolectin/n-decane. The aqueous phase contained $150 \mathrm{mM} \mathrm{KCl}$ and $10 \mathrm{mM}$ 2-(4-(2-Hydroxyethyl)-1-piperazinyl)-ethanesulfonic acid-potassium hydroxide (HEPES- $\mathrm{KOH}) \mathrm{pH} 7$; the temperature was $20^{\circ} \mathrm{C}$. The cis side contained in addition $320 \mathrm{ng} / \mathrm{mL}$ wild-type CyaA (full squares), $320 \mathrm{ng} / \mathrm{mL} \Delta \mathrm{AC}$-CyaA (open squares), or 320 ng/mL CyaA 1008 (full circles) (adapted from [78]). (b) Current-voltage relationships of CyaA pores initiated by negative potential $(-50 \mathrm{mV})$ applied to the cis side. The membranes were formed from asolectin/n-decane. The aqueous phase contained $150 \mathrm{mM} \mathrm{KCl}$ and $10 \mathrm{mM}$ HEPES-KOH pH 7; the temperature was $20{ }^{\circ} \mathrm{C}$. The cis side contained either $20 \mathrm{ng} / \mathrm{mL}$ wild-type CyaA (full circles), $160 \mathrm{ng} / \mathrm{mL}$ wild-type CyaA (full squares), or $320 \mathrm{ng} / \mathrm{mL}$ wild-type CyaA (full triangles) (adapted from [78]). (c) Increase of membrane conductance after the addition of $300 \mathrm{ng} / \mathrm{mL}$ CyaA to the cis side of a black asolectin/n-decane membrane (left side arrow) and of $0.8 \mathrm{mM} \mathrm{Ca}^{2+}$ first to the trans side of the membrane (middle arrow) and then to the cis side of the membrane (right side arrow). The aqueous phase contained $1 \mathrm{M} \mathrm{KCl}, \mathrm{pH} 7$ on both sides of the membrane. The addition of $300 \mathrm{ng} / \mathrm{mL}$ and CyaA added to the cis side of the membrane (left-hand side arrow) resulted in an increase of the membrane conductance (full squares) by a factor of about 100 over control in the absence of CyaA (full points). The addition of $0.8 \mathrm{mM} \mathrm{CaCl}_{2}$ to the trans side (middle arrow) had no impact on membrane conductance, whereas the addition of $0.8 \mathrm{mM} \mathrm{CaCl}_{2}$ to the cis side (right-hand side arrow) led to a dramatic increase of membrane conductance by many orders of magnitude (full squares). The temperature was $20{ }^{\circ} \mathrm{C}$ and $50 \mathrm{mV}$ were applied to the cis side (adapted from [18]). (d) Single-pore recordings of asolectin/n-decane membranes in the presence of a $13 \mathrm{ng} / \mathrm{mL}$ concentration of the purified CyaA-E581K protein (lower line) or intact recombinant CyaA (upper line). Mutant E581K showed an increased pore lifetime, which seems to be linked to an increased hemolytic activity. The applied membrane potential was $50 \mathrm{mV}$, and the temperature was $20^{\circ} \mathrm{C}$ (adapted from [72]).

Pore formation of CyaA was extensively studied with the help of hemolysis assays with osmotic protectants and conductance measurements in black lipid membranes. It was concluded from these studies that CyaA forms transient small cation-selective pores with a diameter of only 0.6-0.8 $\mathrm{nm}$ in contrast to other RTX toxins, such as HlyA of E. coli that has a pore diameter of 2.0-3.0 nm [16,17,79,80]. These results are in line with its relatively low hemolytic activity [81]. 
However, the exact mechanism of AC delivery and hemolysis/pore formation is still not completely understood, and for a long time, there was some disagreement over whether the translocation of the enzymatic component and the oligomerization into cation-selective channels are two distinct mechanisms or if both processes are needed for a successful intoxication. Nowadays, it is assumed that translocation of the enzymatic domain and channel formation are two independent processes, as Rogel and Hanski [13] showed that both activities compete with each other and that the translocation of the AC domain can be uncoupled from membrane insertion of the toxin at low temperature. The full activity can be restored by raising the temperature or adding free calcium [13]. The internalization of $\mathrm{AC}$ seems to be a monomolecular process, while CyaA channel formation involves more than one CyaA molecule in vivo and in vitro $[16,17,32,71,82,83]$. A model established by Osickova et al. suggests that the water-soluble toxin exists in two conformational isomers [71]. After membrane insertion, one isomer mediates the translocation of the catalytic domain, whereas the other one represents a channel precursor (see Figure 3) [71]. This means that AC translocation and the pore-forming activities of CyaA are supposed to be independent and occur in parallel in target cell membranes [71]. One CyaA precursor translocates the AC enzyme domain into the target cell cytosol across the plasma membrane and catalyzes the conversion of cytosolic ATP to cAMP. The other precursor forms a prepore, which might be already able to induce a potassium efflux [74]. The precursor pore finally oligomerizes into a fully functional cation-selective CyaA pore that permeabilizes the membrane bilayer for the efflux of cytosolic potassium ions. The two conformers might exist in an equilibrium, which can be influenced by different factors such as temperature, acylation status, free calcium concentration, antibody binding, and substitution mutations [13,41,42,71,72,74]. According to González-Bullón et al. and Ostolaza et al., these pores increase over time in dependence of toxin concentration and can evolve into large membrane openings of several $\mathrm{nm}$ wide possibly with the participation of membrane lipids (proteolipidic pores) $[84,85]$.
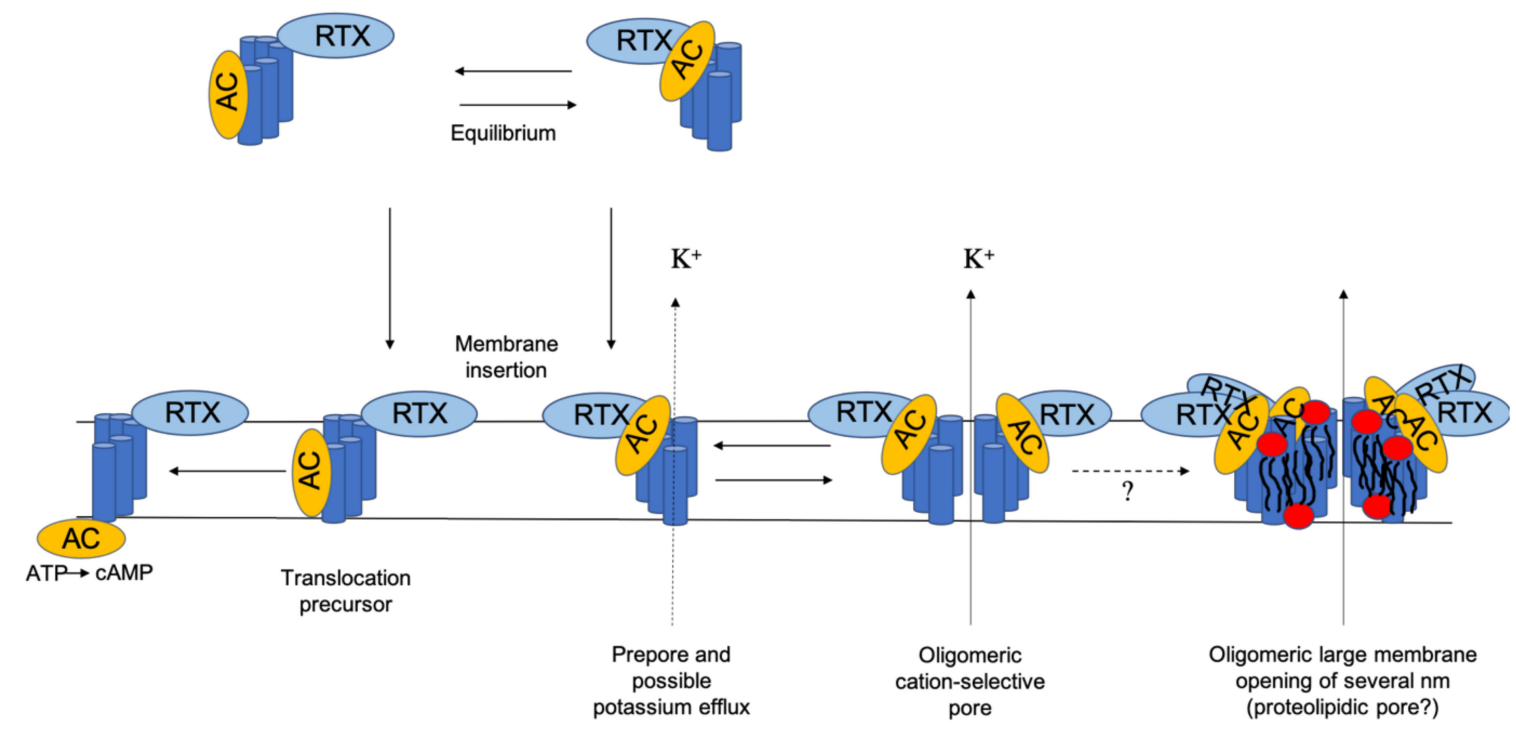

Figure 3. Schematic model of CyaA action on target membranes. Adapted from Osickova et al. [71].

According to this model, hemolysis occurs after membrane adsorption, insertion, and oligomerization of the channel precursor proteins [71,79]. Segments with amphipathic and/or hydrophobic helix-like structures (I: 502-522, II: 529-550, III: 571-593, IV: 607-627, V: 678-698), which possibly insert into host cell membranes, have been predicted for the secondary structure of CyaA [20,71]. Deletions within this region (residue 623-780 and 827-887) prevent the translocation of the AC into the host cell and reduce the hemolytic activity of CyaA [81]. Similarly, it has been shown that tyrosine 940 plays an important role for the CyaA-membrane interaction [86]. The lack of the AC domain (1-373) or the C-terminal nonapeptide-rich part (1009-1706) has no influence on the 
channel properties [86]. The point mutations introduced in these predicted transmembrane structures were found to affect the ability to form pores and play a critical role in cell binding, formation of cation-selective pores, and the translocation of the enzymatic subunit (Figure 2d) [62,71,75]. Mutations affecting the glutamates at position 509 or 516 , which are located in a predicted $\alpha$-helical transmembrane structure in helix I, show a significant altering of the channel properties and the protein translocation [71]. Whereas neutral substitutions have only little effect on the toxin activities, charge exchange by lysine (E509K and E516K) reduces the translocation rate of the catalytic domain as well as the hemolytic activity, ion selectivity, and channel-forming capacity. The substitution of E509 by a helix-breaking proline abolishes totally the invasion of the AC domain, whereas channel formation and cell binding remain unaffected in red blood cells. This is a strong indication that this segment is involved in AC delivery as well as pore formation [71]. The double mutation E509K/E516K further enhanced the hemolytic and pore-forming activity of CyaA [71]. Another pair of glutamate residues, E570 and E581 in helix III, has also been shown to affect CyaA pore-forming activity. Mutant E581K enhanced the hemolytic and pore-forming activity by increasing both the frequency of formation and lifetime of toxin pores (Figure 2d), and double mutation E570K/E581P reduced the specific hemolytic activity [75]. A negative charge at position 570, but not at position 581, was found to be essential for the cation selectivity of the pore, suggesting that E570 might act as ion filter inside or close to the pore mouth [73]. Kurehong et al. focused on the same hydrophobic region and could confirm these results. Mutation of the polar amino acids Q574 and E581 has an influence on the pore-forming activity of CyaA [87]. Similarly, a considerable influence in the membrane penetration and pore-forming activity of CyaA was found for residues 529 to 549 in segment II [19].

Similar results were obtained in studies using the monoclonal antibody 3D1, which recognizes an epitope (amino acids 373-399) at the distal end of the CyaA catalytic domain. The translocation of AC to the cytosol of erythrocytes was inhibited through the binding of the antibody, whereas hemolytic activity increased three to fourfold [88]. A "hyperhemolytic" phenotype was also achieved by the deletion mutant CyaA $\Delta \mathrm{N} 489$ in which the catalytic domain, along with additional amino acids distal to it, was eliminated. This might lead to the assumption that preventing the AC translocation favors a toxin conformation that is more suitable for pore formation [88]. Masin et al. could also achieve a hyperhemolytic CyaA after the substitution of negatively charged residues located in the linker segment of CyaA (residues 400 to 500 of CyaA), which forms an $\alpha$-helical structure interacting with the lipid bilayer [88]. The authors suggest that this "AC to Hly-linking segment" may be responsible for the much smaller conductance and permeability of CyaA pores, as compared to typical RTX hemolysins [89].

Substitution mutations in the putative helix II affect the hemolytic capacity of CyaA without affecting the AC translocating activity (G531P), whereas the substitution of G537, A538, or A546 by diverse residues selectively impaired the ability to translocate the AC domain across the cell membrane [19]. These substitution mutants were still capable of forming transmembrane pores, and therefore, the hemolytic capacity was not affected. The replacement of A538 by proline eliminated the voltage-activated increase of membrane conductivity of CyaA in asolectin membranes [87]. These results show that the linker segment may interact with the structure of helix II and control the formation of CyaA pores [87,88]. Another study proposed that three glycine residues in helix II (G530, G533, and G537) might be a crucial component of the CyaA pore structure and have a role in CyaA oligomerization [90].

Immunolabeling in combination with blue-native polyacrylamide gel electrophoresis (BN-PAGE) of erythrocytes membranes treated with CyaA revealed the presence of rather unstable CyaA oligomers in the erythrocyte membrane with apparent molecular masses of 200, 300, 410, and $470 \mathrm{kDa}$ [75]. Some of them (410 and $470 \mathrm{kDa}$ ) were attributed to the oligomers of the $200 \mathrm{kDa}$ CyaA toxin [75]. This study also revealed a correlation between the oligomerization of CyaA mutants in the membrane, their pore-forming capacity, and their specific hemolytic activity. Mutants of CyaA that showed an enhanced (E581K) or reduced (E570K/ E581P) pore-forming activity and pore lifetime also possessed an 
enhanced or reduced ability to form oligomers in the cell membranes of erythrocyte [73]. New results question this prevailing static model of cell membrane permeabilization by CyaA and propose a new complex and dynamic model in which membrane permeabilization depends on a number of factors, including membrane lipid composition, temperature, time, and toxin concentration (Figure 3) [84,91,92]. González-Bullón et al. showed in cell-sized membrane model systems that CyaA can form-as an initial step—small membrane lesions that can increase in size over time, depending from the available amount of toxin. Apparently, these small lesions can finally develop large membrane pores of several $\mathrm{nm}$ in size. These membrane ruptures might then become eventually large enough to allow the influx of molecules with large molecular mass such as fluorescent dextrans. During this whole process, the vesicle integrity seems to be preserved [84]. This goes in line with a study by Masin et al., where a large-scale membrane disruption by CyaA and the leakage of fluorescein isothiocyanate (FITC) from large, unilamellar vesicles (LUVs) was proposed [91]. González-Bullón et al. reported also that they were able to resolve protein bands with apparent molecular masses of $\approx 550,800,1000$, and $1200 \mathrm{kDa}$ by BN-PAGE, both in lipid vesicles and in cells (macrophages and CR3-negative cells) under lytic conditions [84]. The observed protein bands were interpreted as CyaA trimers, tetramers, pentamers, and hexamers [84], and these are in agreement with studies showing that the hemolysis of CyaA is a cooperative event with a hill number $\geq 3$ [17]. However, the reported BN-PAGE bands are somewhat bigger then the previously ones reported by Vojtova-Vodolanova et al. [75]. The reason for this discrepancy is explained by the shorter exposition time of CyaA to sheep erythrocytes (30 min), and it is assumed that a longer exposer time would have resulted in larger CyaA oligomers [84]. It was speculated by Ostolaza et al. in a recent review on biological activity of RTX toxins [85] and González-Bullón et al. [85] that CyaA pores can be as large as listeriolysins and toroidal (proteolipidic) pores. Both studies postulate a "sequential" mode of oligomerization, which involves the successive addition of units with the same stoichiometry (Figure 3) [84,85].

The same group through atomic force microscope (AFM) imaging could confirm these results. Different CyaA structures of heterogeneous composition were detected. They formed lines, arcs, or closed rings in phosphatidylcholine vesicles. These structures are believed to be transmembrane pores with variable diameters of up to $\approx 20 \mathrm{~nm}$ in the narrowest and of up to $\approx 50-60 \mathrm{~nm}$ in the more external part [84]. So far, any other groups have not repeated these results. It remains to be elucidated why the hemolytic activity on red blood cells is small when such large transmembrane structures are formed. However, it appears that the invasive AC activity and pore formation synergize and increase the potency of the overall toxicity of CyaA on target cells, in particular on CD11b+ cells [61,93]. This has probably to do with the influx of $\mathrm{Ca}^{2+}$ ions through the CyaA channels and the subsequently increased activity of the AC domain to form cAMP.

\section{Factors Affecting CyaA Channel-Forming Activity: Effect of Calcium Ions, Membrane Potential, and $\mathrm{pH}$}

Free calcium ions at concentrations above $0.1 \mathrm{mM} \mathrm{Ca}^{2+}$ induce important conformational changes of the repeat domain, which are essential for the CyaA biological activity [33,34]. This includes target cell binding, the hemolytic activity, and the capacity to translocate the enzymatic domain of AC of B. pertussis into host cells [41,94]. Rogel and Hanski showed that after a single exposure to calcium, CyaA becomes competent for membrane insertion and hemolytic activity, even without free calcium ions, assuming that calcium ions are firmly bound to CyaA [13].

Black lipid bilayer experiments with membranes made from asolectin proved that the conductance of CyaA channels is independent of the calcium concentration within the range between 0.5 and $10 \mathrm{mM}$ $\mathrm{CaCl}_{2}$ (about $40 \mathrm{pS}$ in the presence or absence of $\mathrm{CaCl}_{2}$ ) [18]. When $\mathrm{CaCl}_{2}$ concentration was raised to $0.8 \mathrm{mM}$ on the cis-side - the side of the addition of CyaA-the membrane conductance increased substantially by more than 1000-fold (Figure 2c) [18]. This suggests that calcium ions influenced only the frequency of channel formation but not its conductance [18]. The minimum effective calcium concentration necessary to mediate this increase was about $0.6-0.8 \mathrm{mM} \mathrm{CaCl}_{2}$, depending on the 
ionic strength of the aqueous phase. The maximum calcium ion-mediated effect on the increase of membrane conductance was reached at about $10 \mathrm{mM} \mathrm{CaCl}_{2}$ with a half saturation constant of about 2 to $4 \mathrm{mM}$. When the repeat domain of $\mathrm{CyaA}$ was partially or fully deleted, the addition of $\mathrm{CaCl}_{2}$ did not influence the frequency of channel formation [18]. Additional experiments on target cells or black lipid bilayer membranes with fragments derived from the RTX domain were able to show that these fragments complement inactive CyaA molecules that lack different blocks within the repeat domains [95]. Full biological activity was achieved for the truncated CyaA variant CyaA (1-1490) when complemented with the two partial RTX-domain derived sequences CyaA (1006-1706) (full length RTX-sequence) or CyaA (1490-1681) being added to the experimental setup in the presence of $1 \mathrm{mM} \mathrm{CaCl}_{2}$ [95]. The addition of the partial RTX sequences had no influence on membrane activity of the truncated form when calcium ions were absent in the experiments. These results were supported by studies where truncated forms of CyaA were not able to intoxicate target cells or where an inactive truncated CyaA molecule that lacks the $76 \mathrm{C}$-terminal amino acids could be fully restored to its toxic activity when a polypeptide comprising these $217 \mathrm{C}$-terminal residues of CyaA was added to the inactive CyaA derivative [76,77]. However, lipid bilayer experiments with CyaA in the presence of calmodulin suggested that it was not able to interfere with the calcium-dependent activation of CyaA pores [78].

The membrane potential is another important factor for the biological activity of CyaA. Patch clamp studies showed that the AC delivery into certain target cells was dependent on a negative membrane potential [96]. Atrial cells could only be successfully intoxicated when held at a negative potential, whereas under positive potential, no toxin activity could be observed [96]. Knapp et al. could show that CyaA forms different pores in lipid bilayer experiments depending on the orientation of the electrical potential across the membrane [78]. When CyaA was added at the membrane side facing a positive potential, pores with a defined size were formed and conductance increased rather rapidly. However, when the toxin was added to the side at negative potential, CyaA behaved more detergent-like and a showed reduced ability to form pores [78]. Experiments with the deletion mutation of CyaA ( $\triangle \mathrm{AC}$ and ACT 1008, i.e., deletions of amino acids 1008 to 1490) proved that the voltage sensor must be located within the residues 400 and 1008 (most likely in the pore-forming segment), since these deletion mutants behaved similar to wild-type CyaA (Figure 2a). Pore formation under positive potential resulted in a strongly increasing membrane current, whereas when pore formation occurred under negative potential, the membrane current decreased or remained at a constant level (Figure 2a,b) [78]. Moreover, calcium ions in millimolar concentration were found to enhance the voltage dependence of CyaA pores [78]. Veneziano et al. observed similar results when studying the translocation of the AC domain across tethered lipid bilayers; the translocation of the AC domain was strictly dependent on the presence of calcium and the application of a negative electrical potential across the membrane [49]. However, CyaA provokes colloid-osmotic cell lysis or delivers its AC domain efficiently even into cells with low membrane potential, such as sheep erythrocytes [7,97]. As discussed above, it is also able to release or allow an influx of marker substances from multilamellar liposomes devoid of membrane potential [84,91,98]. Whether the lack of a membrane potential is responsible for the observed CyaA structures in membrane, as postulated by González-Bullón et al. [84] or not, remains to be open at present and needs to be addressed in further studies.

The single-pore conductance was strongly affected by the variation of $\mathrm{pH}$ and increased in $1 \mathrm{M}$ $\mathrm{KCl}$ with increasing $\mathrm{pH}$ from about $4 \mathrm{pS}$ at $\mathrm{pH} 5$ to about $60 \mathrm{pS}$ at $\mathrm{pH} 9$ [78]. The ion selectivity remained unaffected by $\mathrm{pH}$. Experiments with CyaA mutants revealed that the adenylate cyclase (AC) and repeat (RT) domains were not involved in voltage and $\mathrm{pH}$ sensing [78].

\section{Conclusions}

The adenylate cyclase toxin of $B$. pertussis is one of the main virulence factors of this bacterium and was studied intensively in the last three decades. However, the exact mechanism of CyaA transport into the target cells, which is also interesting for biotechnological applications [65], is still 
not fully understood. The current model of the activity of CyaA-membrane binding via receptor or not, membrane insertion, translocation of the AC domain and formation of an oligomeric pore-is challenged by results regarding the new enzymatic activities of $\mathrm{CyaA}$ and the mechanisms of membrane permeabilization, of pore assembly, and its relation to the translocation of the AC domain. In order to reconcile these new results with the older ones, it is important that these results will be verified by other groups and by the use of different methods. A special focus has to be set on pore formation, since it is possible that the pore-forming activities of RTX toxins allow the permeation of small molecules through the target cell membrane, including calcium ions, which start the inflammatory reactions and possibly cell lysis [99-101]. The activity and the biophysical characteristics of pore formation by CyaA may trigger a strong impact of the toxin's bacterial virulence. Nevertheless, it has to be considered that the pore-forming activity of RTX-toxins, although being essential for virulence, may represent an indirect mechanism of toxicity in the case of CyaA. Unfortunately, not too much is known about the 3D structure of the RTX toxin channels. For this reason, it must be speculated for an individual RTX toxin whether a single molecule or an oligomer is involved in transmembrane pore formation. However, at least for the hemolysin of E. coli and CyaA of B. pertussis, it has been shown that the pore-forming unit is an oligomer $[75,102]$.

Author Contributions: Writing—Original draft preparation, O.K.; Writing—Review and editing, R.B. All authors have read and agreed to the published version of the manuscript.

Funding: This research received no external funding.

Conflicts of Interest: The authors declare no conflict of interest.

\section{References}

1. Dorji, D.; Mooi, F.; Yantorno, O.; Deora, R.; Graham, R.M.; Mukkur, T.K. Bordetella pertussis virulence factors in the continuing evolution of whooping cough vaccines for improved performance. Med. Microbiol. Immunol. 2018, 207, 3-26. [CrossRef] [PubMed]

2. Ludwig, A.; Göbel, W. The family of the multigenic encoded RTX toxins. In The Comprehensive Sourcebook of Bacterial Protein Toxins, 2nd ed.; Alouf, J.E., Freer, J.H., Eds.; Academic Press: Cambridge, UK, 1999; pp. 330-348.

3. Sebo, P.; Osicka, R.; Masin, J. Adenylate cyclase toxin-hemolysin relevance for pertussis vaccines. Expert Rev. Vaccines. 2014, 13, 1215-1227. [CrossRef] [PubMed]

4. Weiss, A.A.; Hewlett, E.L. Virulence factors of Bordetella pertussis. Annu. Rev. Microbiol. 1986, 40, 661-686. [CrossRef]

5. Sebo, P.A. Meeting of good friends: When the cell biology of prokaryotes and eukaryotes meet. Folia Microbiol. 1998, 43, 235-238. [CrossRef]

6. Goodwin, M.S.; Weiss, A.A. Adenylate cyclase toxin is critical for colonization and pertussis toxin is critical for lethal infection by Bordetella pertussis in infant mice. Infect. Immun. 1990, 58, 3445-3447. [CrossRef] [PubMed]

7. Confer, D.L.; Eaton, J.W. Phagocyte impotence caused by an invasive bacterial adenylate cyclase. Science 1982, 217, 948-950. [CrossRef]

8. Gueirard, P.; Druilhe, A.; Pretolani, M.; Guiso, N. Role of adenylate cyclase-hemolysin in alveolar macrophage apoptosis during Bordetella pertussis infection in vivo. Infect. Immun. 1998, 66, 1718-1725. [CrossRef]

9. Harvill, E.T.; Cotter, P.A.; Yuk, M.H.; Miller, J.F. Probing the function of Bordetella bronchiseptica adenylate cyclase toxin by manipulating host immunity. Infect. Immun. 1999, 67, 1493-1500. [CrossRef]

10. Khelef, N.; Guiso, N. Induction of macrophage apoptosis by Bordetella pertussis adenylate cyclase-hemolysin. FEMS Microbiol. Lett. 1995, 134, 27-32. [CrossRef]

11. Khelef, N.; Zychlinsky, A.; Guiso, N. Bordetella pertussis induces apoptosis in macrophages: Role of adenylate cyclase-hemolysin. Infect. Immun. 1993, 61, 4064-4071. [CrossRef]

12. Fedele, G.; Schiavoni, I.; Adkins, I.; Klimova, N.; Sebo, P. Invasion of dendritic cells, macrophages and neutrophils by the bordetella adenylate cyclase toxin: A subversive move to fool host immunity. Toxins 2017, 9, 293. [CrossRef] [PubMed] 
13. Rogel, A.; Hanski, E. Distinct steps in the penetration of adenylate cyclase toxin of Bordetella pertussis into sheep erythrocytes. Translocation of the toxin across the membrane. J. Biol. Chem. 1992, 267, 22599-22605. [PubMed]

14. Ahuja, N.; Kumar, P.; Bhatnagar, R. The adenylate cyclase toxins. Crit. Rev. Microbiol. 2004, 30, 187-196. [CrossRef] [PubMed]

15. Sakamoto, H.; Bellalou, J.; Sebo, P.; Ladant, D. Bordetella pertussis adenylate cyclase toxin. Structural and functional independence of the catalytic and hemolytic activities. J. Biol. Chem. 1992, 267, 13598-13602. [PubMed]

16. Benz, R.; Maier, E.; Ladant, D.; Ullmann, A.; Sebo, P. Adenylate cyclase toxin (CyaA) of Bordetella pertussis. Evidence for the formation of small ion-permeable channels and comparison with HlyA of Escherichia coli. J. Biol. Chem. 1994, 269, 27231-27239. [PubMed]

17. Szabo, G.; Gray, M.C.; Hewlett, E.L. Adenylate cyclase toxin from Bordetella pertussis produces ion conductance across artificial lipid bilayers in a calcium- and polarity-dependent manner. J. Biol. Chem. 1994, 269, 22496-22499. [PubMed]

18. Knapp, O.; Maier, E.; Polleichtner, G.; Masín, J.; Sebo, P.; Benz, R. Channel formation in model membranes by the adenylate cyclase toxin of Bordetella pertussis: Effect of calcium. Biochemistry 2003, 42, 8077-8084. [CrossRef]

19. Roderova, J.; Osickova, A.; Sukova, A.; Mikusova, G.; Fiser, R.; Sebo, P.; Osicka, R.; Masin, J. Residues 529 to 549 participate in membrane penetration and pore-forming activity of the Bordetella adenylate cyclase toxin. Sci. Rep. 2019, 9, 5758. [CrossRef]

20. Powthongchin, B.; Angsuthanasombat, C. Effects on haemolytic activity of single proline substitutions in the Bordetella pertussis CyaA pore-forming fragment. Arch. Microbiol. 2009, 191, 1-9. [CrossRef]

21. Kurehong, C.; Powthongchin, B.; Thamwiriyasati, N.; Angsuthanasombat, C. Functional significance of the highly conserved Glu(570) in the putative pore-forming helix 3 of the Bordetella pertussis haemolysin toxin. Toxicon 2011, 57, 897-903. [CrossRef]

22. Prangkio, P.; Juntapremjit, S.; Koehler, M.; Hinterdorfer, P.; Angsuthanasombat, C. Contributions of the Hydrophobic Helix 2 of the Bordetella pertussis CyaA-hemolysin to Membrane Permeabilization. Protein Pept. Lett. 2018, 25, 236-243. [CrossRef] [PubMed]

23. Ludwig, A.; Vogel, M.; Goebel, W. Mutations affecting activity and transport of haemolysin in Escherichia coli. Mol. Gen. Genet. 1987, 206, 238-245. [CrossRef] [PubMed]

24. Hackett, M.; Walker, C.B.; Guo, L.; Gray, M.C.; Van Cuyk, S.; Ullmann, A.; Shabanowitz, J.; Hunt, D.F.; Hewlett, E.L.; Sebo, P. Hemolytic, but not cell-invasive activity, of adenylate cyclase toxin is selectively affected by differential fatty-acylation in Escherichia coli. J. Biol. Chem. 1995, 270, 20250-20253. [CrossRef] [PubMed]

25. Masin, J.; Basler, M.; Knapp, O.; El-Azami-El-Idrissi, M.; Maier, E.; Konopasek, I.; Benz, R.; Leclerc, C.; Sebo, P. Acylation of lysine 860 allows tight binding and cytotoxicity of Bordetella adenylate cyclase on CD11b-expressing cells. Biochemistry 2005, 44, 12759-12766. [CrossRef] [PubMed]

26. Westrop, G.D.; Hormozi, E.K.; Da Costa, N.A.; Parton, R.; Coote, J.G. Bordetella pertussis adenylate cyclase toxin: ProCyaA and CyaC proteins synthesised separately in Escherichia coli produce active toxin in vitro. Gene 1996, 180, 91-99. [CrossRef]

27. Barry, E.M.; Weiss, A.A.; Ehrmann, I.E.; Gray, M.C.; Hewlett, E.L.; Goodwin, M.S. Bordetella pertussis adenylate cyclase toxin and hemolytic activities require a second gene, cyaC, for activation. J. Bacteriol. 1991, 173, 720-726. [CrossRef]

28. Basar, T.; Havlícek, V.; Bezousková, S.; Hackett, M.; Sebo, P. Acylation of lysine 983 is sufficient for toxin activity of Bordetella pertussis adenylate cyclase. Substitutions of alanine 140 modulate acylation site selectivity of the toxin acyltransferase CyaC. J. Biol. Chem. 2001, 276, 348-354. [CrossRef]

29. Basar, T.; Havlícek, V.; Bezousková, S.; Halada, P.; Hackett, M.; Sebo, P. The conserved lysine 860 in the additional fatty-acylation site of Bordetella pertussis adenylate cyclase is crucial for toxin function independently of its acylation status. J. Biol. Chem. 1999, 274, 10777-10783. [CrossRef]

30. Masin, J.; Osicka, R.; Bumba, L.; Sebo, P. Bordetella adenylate cyclase toxin: A unique combination of a pore-forming moiety with a cell-invading adenylate cyclase enzyme. Pathog. Dis. 2015, 73. [CrossRef] 
31. O'Brien, D.P.; Cannella, S.E.; Voegele, A.; Raoux-Barbot, D.; Davi, M.; Douché, T.; Matondo, M.; Brier, S.; Ladant, D.; Chenal, A. Post-translational acylation controls the folding and functions of the CyaA RTX toxin. FASEB J. 2019, 33, 10065-10076. [CrossRef]

32. Linhartová, I.; Bumba, L.; Mašín, J.; Basler, M.; Osička, R.; Kamanová, J.; Procházková, K.; Adkins, I.; Hejnová-Holubová, J.; Sadílková, L.; et al. RTX proteins: A highly diverse family secreted by a common mechanism. FEMS Microbiol. Rev. 2010, 34, 1076-1112. [CrossRef] [PubMed]

33. Baumann, U.; Wu, S.; Flaherty, K.M.; McKay, D.B. Three-dimensional structure of the alkaline protease of Pseudomonas aeruginosa: A two-domain protein with a calcium binding parallel beta roll motif. EMBO J. 1993, 12, 3357-3364. [CrossRef] [PubMed]

34. Baumann, U. Structure-function relationships of the repeat domains of RTX toxins. Toxins 2019, 11, 657. [CrossRef] [PubMed]

35. Ludwig, A.; Jarchau, T.; Benz, R.; Goebel, W. The repeat domain of Escherichia coli haemolysin (HlyA) is responsible for its Ca2+-dependent binding to erythrocytes. Mol. Gen. Genet. 1988, 214, 553-561. [CrossRef]

36. Benz, R. Channel formation by RTX-toxins of pathogenic bacteria: Basis of their biological activity. Biochim. Biophys. Acta 2016, 1858, 526-537. [CrossRef]

37. Coote, J.G. Structural and functional relationships among the RTX toxin determinants of gram-negative bacteria. FEMS Microbiol. Rev. 1992, 8, 137-161. [CrossRef]

38. El-Azami-El-Idrissi, M.; Bauche, C.; Loucka, J.; Osicka, R.; Sebo, P.; Ladant, D.; Leclerc, C. Interaction of Bordetella pertussis adenylate cyclase with CD11b/CD18: Role of toxin acylation and identification of the main integrin interaction domain. J. Biol. Chem. 2003, 278, 38514-38521. [CrossRef]

39. Guermonprez, P.; Khelef, N.; Blouin, E.; Rieu, P.; Ricciardi-Castagnoli, P.; Guiso, N.; Ladant, D.; Leclerc, C. The adenylate cyclase toxin of Bordetella pertussis binds to target cells via the alpha(M)beta(2) integrin (CD11b/CD18). J. Exp. Med. 2001, 193, 1035-1044. [CrossRef]

40. Morova, J.; Osicka, R.; Masin, J.; Sebo, P. RTX cytotoxins recognize beta2 integrin receptors through N-linked oligosaccharides. Proc. Natl. Acad. Sci. USA 2008, 105, 5355-5360. [CrossRef]

41. Rose, T.; Sebo, P.; Bellalou, J.; Ladant, D. Interaction of calcium with Bordetella pertussis adenylate cyclase toxin. Characterization of multiple calcium-binding sites and calcium-induced conformational changes. J. Biol. Chem. 1995, 270, 26370-26376. [CrossRef]

42. Rhodes, C.R.; Gray, M.C.; Watson, J.M.; Muratore, T.L.; Kim, S.B.; Hewlett, E.L.; Grisham, C.M. Structural consequences of divalent metal binding by the adenylyl cyclase toxin of Bordetella pertussis. Arch. Biochem Biophys. 2001, 395, 169-176. [CrossRef] [PubMed]

43. Glaser, P.; Sakamoto, H.; Bellalou, J.; Ullmann, A.; Danchin, A. Secretion of cyclolysin, the calmodulin-sensitive adenylate cyclase-haemolysin bifunctional protein of Bordetella pertussis. EMBO J. 1988, 7, 3997-4004. [CrossRef] [PubMed]

44. Masure, H.R.; Au, D.C.; Gross, M.K.; Donovan, M.G.; Storm, D.R. Secretion of the Bordetella pertussis adenylate cyclase from Escherichia coli containing the hemolysin operon. Biochemistry 1990, 29, 140-145. [CrossRef] [PubMed]

45. Mackman, N.; Nicaud, J.M.; Gray, L.; Holland, I.B. Genetical and functional organisation of the Escherichia coli haemolysin determinant 2001. Mol. Gen. Genet. 1985, 201, 282-288. [CrossRef]

46. Benz, R.; Maier, E.; Gentschev, I. TolC of Escherichia coli functions as an outer membrane channel. Zent. Bakteriol. 1993, 278, 187-196. [CrossRef]

47. Koronakis, V.; Sharff, A.; Koronakis, E.; Luisi, B.; Hughes, C. Crystal structure of the bacterial membrane protein TolC central to multidrug efflux and protein export. Nature 2000, 405, 914-919. [CrossRef]

48. Zaretzky, F.R.; Gray, M.C.; Hewlett, E.L. Mechanism of association of adenylate cyclase toxin with the surface of Bordetella pertussis: A role for toxin-filamentous haemagglutinin interaction. Mol. Microbiol. 2002, 45, 1589-1598. [CrossRef]

49. Veneziano, R.; Rossi, C.; Chenal, A.; Devoisselle, J.M.; Ladant, D.; Chopineau, J. Bordetella pertussis adenylate cyclase toxin translocation across a tethered lipid bilayer. Proc. Natl. Acad. Sci. USA 2013, 110, 20473-20478. [CrossRef]

50. Sanchez-Magraner, L.; Viguera, A.R.; Garcia-Pacios, M.; Garcillán, M.P.; Arrondo, J.L.; del la Cruz, F.; Goni, F.M.; Ostolaza, H. The calcium-binding C-terminal domain of Escherichia coli alpha-hemolysin is a major determinant in the surface-active properties of the protein. J. Biol. Chem. 2007, 282, 11827-11835. [CrossRef] 
51. Wolff, J.; Cook, G.H.; Goldhammer, A.R.; Berkowitz, S.A. Calmodulin activates prokaryotic adenylate cyclase. Proc. Natl. Acad. Sci. USA 1980, 77, 3841-3844. [CrossRef]

52. Weingart, C.L.; Weiss, A.A. Bordetella pertussis virulence factors affect phagocytosis by human neutrophils. Infect. Immun. 2000, 68, 1735-1739. [CrossRef] [PubMed]

53. Friedman, R.L.; Fiederlein, R.L.; Glasser, L.; Galgiani, J.N. Bordetella pertussis adenylate cyclase: Effects of affinity-purified adenylate cyclase on human polymorphonuclear leukocyte functions. Infect. Immun. 1987, 55, 135-140. [CrossRef]

54. Vojtova, J.; Kamanova, J.; Sebo, P. Bordetella adenylate cyclase toxin: A swift saboteur of host defense. Curr. Opin. Microbiol. 2006, 9, 69-75. [CrossRef] [PubMed]

55. Bachelet, M.; Richard, M.J.; Francois, D.; Polla, B.S. Mitochondrial alterations precede Bordetella pertussis-induced apoptosis. FEMS Immunol. Med. Mic. 2002, 32, 125-131. [CrossRef] [PubMed]

56. Guo, Q.; Shen, Y.; Lee, Y.S.; Gibbs, C.S.; Mrksich, M.; Tang, W.J. Structural basis for the interaction of Bordetella pertussis adenylyl cyclase toxin with calmodulin. EMBO J. 2005, 24, 3190-3201. [CrossRef] [PubMed]

57. Gentile, F.; Raptis, A.; Knipling, L.G.; Wolff, J. Bordetella pertussis adenylate cyclase. Penetration into host cells. Eur. J. Biochem. 1988, 175, 447-453. [CrossRef]

58. Gordon, V.M.; Leppla, S.H.; Hewlett, E.L. Inhibitors of receptor-mediated endocytosis block the entry of Bacillus anthracis adenylate cyclase toxin but not that of Bordetella pertussis adenylate cyclase toxin. Infect. Immun. 1988, 56, 1066-1069. [CrossRef]

59. Guermonprez, P.; Ladant, D.; Karimova, G.; Ullmann, A.; Leclerc, C. Direct delivery of the Bordetella pertussis adenylate cyclase toxin to the MHC class I antigen presentation pathway. J. Immunol. 1999, 162, 1910-1916.

60. Schlecht, G.; Loucka, J.; Najar, H.; Sebo, P.; Leclerc, C. Antigen targeting to CD11b allows efficient presentation of CD4+ and CD8+ T cell epitopes and in vivo Th1-polarized T cell priming. J. Immunol. 2004, 173, 6089-6097. [CrossRef]

61. Basler, M.; Masin, J.; Osicka, R.; Sebo, P. Pore-forming and enzymatic activities of Bordetella pertussis adenylate cyclase toxin synergize in promoting lysis of monocytes. Infect. Immun. 2006, 74, 2207-2214. [CrossRef]

62. Fiser, R.; Masin, J.; Basler, M.; Krusek, J.; Spulakova, V.; Konopasek, I.; Sebo, P. Third activity of Bordetella adenylate cyclase (AC) toxin-hemolysin. Membrane translocation of AC domain polypeptide promotes calcium influx into CD11b+ monocytes independently of the catalytic and hemolytic activities. J. Biol. Chem. 2007, 282, 2808-2820. [CrossRef] [PubMed]

63. Bumba, L.; Masin, J.; Fiser, R.; Sebo, P. Bordetella adenylate cyclase toxin mobilizes its b2 integrin receptor into lipid rafts to accomplish translocation across target cell membrane in two steps. PLoS Pathog. 2010, 6, e1000901. [CrossRef] [PubMed]

64. Voegele, A.; Subrini, O.; Sapay, N.; Ladant, D.; Chenal, A. Membrane-active properties of an amphitropic peptide from the CyaA toxin translocation region. Toxins 2017, 9, 369. [CrossRef]

65. Chenal, A.; Ladant, D. Bioengineering of bordetella pertussis adenylate cyclase toxin for antigen-delivery and immunotherapy. Toxins 2018, 10, 302. [CrossRef] [PubMed]

66. González-Bullón, D.; Uribe, K.B.; Martín, C.; Ostolaza, H. Phospholipase a activity of adenylate cyclase toxin mediates translocation of its adenylate cyclase domain. Proc. Natl. Acad. Sci. USA 2017, 114, E6784-E6793. [CrossRef] [PubMed]

67. Bumba, L.; Masin, J.; Osickova, A.; Osicka, R.; Sebo, P. Bordetella pertussis adenylate cyclase toxin does not possess a phospholipase a activity; Serine 606 and aspartate 1079 residues are not involved in target cell delivery of the adenylyl cyclase enzyme domain. Toxins 2018, 10, 245. [CrossRef]

68. Voegele, A.; Sadi, M.; Raoux-Barbot, D.; Douché, T.; Matondo, M.; Ladant, D.; Chenal, A. The adenylate cyclase (CyaA) toxin from Bordetella pertussis has no detectable phospholipase A (PLA) activity in vitro. Toxins 2019, 11, 111. [CrossRef]

69. González-Bullón, D.; Martin, C.; Ostolaza, H. Characterization of the intrinsic phospholipase A1 activity of bordetella pertussis adenylate cyclase toxin. Toxins 2018, 10, 514. [CrossRef]

70. Maier, E.; Reinhard, N.; Benz, R.; Frey, J. Channel-forming activity and channel size of the RTX toxins ApxI, ApxII, and ApxIII of Actinobacillus pleuropneumoniae. Infect. Immun. 1996, 64, 4415-4423. [CrossRef]

71. Osickova, A.; Osicka, R.; Maier, E.; Benz, R.; Sebo, P. An amphipathic alpha-helix including glutamates 509 and 516 is crucial for membrane translocation of adenylate cyclase toxin and modulates formation and cation selectivity of its membrane channels. J. Biol. Chem. 1999, 274, 37644-37650. 
72. Basler, M.; Knapp, O.; Masin, J.; Fiser, R.; Maier, E.; Benz, R.; Sebo, P.; Osicka, R. Segments crucial for membrane translocation and poreforming activity of Bordetella adenylate cyclase toxin. J. Biol. Chem. 2007, 282, 12419-12429. [CrossRef] [PubMed]

73. Betsou, F.; Sebo, P.; Guiso, N. CyaC-mediated activation is important not only for toxic but also for protective activities of Bordetella pertussis adenylate cyclase-hemolysin. Infect. Immun. 1993, 61, 3583-3589. [CrossRef]

74. Gray, M.; Szabo, G.; Otero, A.S.; Gray, L.; Hewlett, E. Distinct mechanisms for K+ efflux, intoxication, and hemolysis by Bordetella pertussis AC toxin. J. Biol. Chem. 1998, 273, 18260-18267. [CrossRef]

75. Vojtova-Vodolanova, J.; Basler, M.; Osicka, R.; Knapp, O.; Maier, E.; Cerny, J.; Benada, O.; Benz, R.; Sebo, P. Oligomerization is involved in pore formation by Bordetella adenylate cyclase toxin. FASEB J. 2009, 23, 2831-2843. [CrossRef] [PubMed]

76. Iwaki, M.; Ullmann, A.; Sebo, P. Identification by in vitro complementation of regions required for cell-invasive activity of Bordetella pertussis adenylate cyclase toxin. Mol. Microbiol. 1995, 17, 1015-1024. [CrossRef] [PubMed]

77. Bejerano, M.; Nisan, I.; Ludwig, A.; Goebel, W.; Hanski, E. Characterization of the C-terminal domain essential for toxic activity of adenylate cyclase toxin. Mol. Microbiol. 1999, 31, 381-392. [CrossRef] [PubMed]

78. Knapp, O.; Maier, E.; Masín, J.; Sebo, P.; Benz, R. Pore formation by the Bordetella adenylate cyclase toxin in lipid bilayer membranes: Role of voltage and pH. Biochim. Biophys. Acta 2008, 1778, 260-269. [CrossRef]

79. Osickova, A.; Masin, J.; Fayolle, C.; Krusek, J.; Basler, M.; Pospisilova, E.; Leclerc, C.; Osicka, R.; Sebo, P. Adenylate cyclase toxin translocates across target cell membrane without forming a pore. Mol. Microbiol. 2010, 75, 1550-1562. [CrossRef]

80. Ehrmann, I.E.; Gray, M.C.; Gordon, V.M.; Gray, L.S.; Hewlett, E.L. Hemolytic activity of adenylate cyclase toxin from Bordetella pertussis. FEBS Lett. 1991, 278, 79-83.

81. Bellalou, J.; Sakamoto, H.; Ladant, D.; Geoffroy, C.; Ullmann, A. Deletions affecting hemolytic and toxin activities of Bordetella pertussis adenylate cyclase. Infect. Immun. 1990, 58, 3242-3247. [CrossRef]

82. Cannella, S.E.; Enguné, V.Y.N.; Davi, M.; Malosse, C.; Sotomayor Pérez, A.C.; Chamot-Rooke, J.; Vachette, P.; Durand, D.; Ladant, D.; Chenal, A. Stability, structural and functional properties of a monomeric, calcium-loaded adenylate cyclase toxin, CyaA, from Bordetella pertussis. Sci. Rep. 2017, 7, 42065. [CrossRef] [PubMed]

83. Voegele, A.; O’Brien, D.P.; Subrini, O.; Sapay, N.; Cannella, S.E.; Enguéné, V.Y.N.; Hessel, A.; Karst, J.; Hourdel, V.; Perez, A.C.S.; et al. Translocation and calmodulin-activation of the adenylate cyclase toxin (CyaA) of Bordetella pertussis. Pathog. Dis. 2018, 76. [CrossRef] [PubMed]

84. González-Bullón, D.; Uribe, K.B.; Largo, E.; Guembelzu, G.; García-Arribas, A.B.; Martín, C.; Ostolaza, H. Membrane permeabilization by Bordetella adenylate cyclase toxin involves pores of tunable size. Biomolecules 2019, 9, 183. [CrossRef] [PubMed]

85. Ostolaza, H.; González-Bullón, D.; Uribe, K.B.; Martín, C.; Amuategi, J.; Fernandez-Martínez, X. Membrane permeabilization by pore-forming RTX toxins: What kind of lesions do these toxins form? Toxins 2019, 11, 354. [CrossRef] [PubMed]

86. Masin, J.; Roderova, J.; Osickova, A.; Novak, P.; Bumba, L.; Fiser, R.; Sebo, P.; Osicka, R. The conserved tyrosine residue 940 plays a key structural role in membrane interaction of Bordetella adenylate cyclase toxin. Sci. Rep. 2017, 7, 9330. [CrossRef]

87. Kurehong, C.; Kanchanawarin, C.; Powthongchin, B.; Prangkio, P.; Katzenmeier, G.; Angsuthanasombat, C. Functional contributions of positive charges in the pore-lining helix 3 of the Bordetella pertussis CyaA-hemolysin to hemolytic activity and ion-channel opening. Toxins 2017, 9, 109. [CrossRef]

88. Gray, M.C.; Lee, S.J.; Gray, L.S.; Zaretzky, F.R.; Otero, A.S.; Szabo, G.; Hewlett, E.L. Translocation-specific conformation of adenylate cyclase toxin from Bordetella pertussis inhibits toxin-mediated hemolysis. J. Bacteriol. 2001, 183, 5904-5910. [CrossRef]

89. Masin, J.; Osickova, A.; Sukova, A.; Fiser, R.; Halada, P.; Bumba, L.; Linhartova, I.; Osicka, R.; Sebo, P. Negatively charged residues of the segment linking the enzyme and cytolysin moieties restrict the membrane-permeabilizing capacity of adenylate cyclase toxin. Sci. Rep. 2016, 6, 29137. [CrossRef]

90. Juntapremjit, S.; Thamwiriyasati, N.; Kurehong, C.; Prangkio, P.; Shank, L.; Powthongchin, B.; Angsuthanasombat, C. Functional importance of the Gly cluster in transmembrane helix 2 of the Bordetella pertussis CyaA-hemolysin: Implications for toxin oligomerization and pore formation. Toxicon 2015, 106, 14-19. [CrossRef] 
91. Masin, J.; Konopasek, I.; Svobodova, J.; Sebo, P. Different structural requirements for adenylate cyclase toxin interactions with erythrocyte and liposome membranes. Biochim. Biophys. Acta 2004, 1660, 144-154. [CrossRef] [PubMed]

92. Moayeri, M.; Welch, R.A. Effects of temperature, time, and toxin concentration on lesion formation by the Escherichia coli hemolysin. Infect. Immun. 1994, 62, 4124-4134. [CrossRef] [PubMed]

93. Hewlett, E.L.; Donato, G.M.; Gray, M.C. Macrophage cytotoxicity produced by adenylate cyclase toxin from Bordetella pertussis: More than just making cyclic AMP! Mol. Microbiol. 2006, 59, 447-459. [CrossRef] [PubMed]

94. Hewlett, E.L.; Gordon, V.M.; McCaffery, J.D.; Sutherland, W.M.; Gray, M.C. Adenylate cyclase toxin from Bordetella pertussis. Identification and purification of the holotoxin molecule. J. Biol. Chem. 1989, 264, 19379-19384. [PubMed]

95. Bauche, C.; Chenal, A.; Knapp, O.; Bodenreider, C.; Benz, R.; Chaffotte, A.; Ladant, D. Structural and functional characterization of an essential RTX subdomain of Bordetella pertussis adenylate cyclase toxin. J. Biol. Chem. 2006, 281, 16914-16926. [CrossRef]

96. Otero, A.S.; Yi, X.B.; Gray, M.C.; Szabo, G.; Hewlett, E.L. Membrane depolarization prevents cell invasion by Bordetella pertussis adenylate cyclase toxin. J. Biol. Chem. 1995, 270, 9695-9697. [CrossRef]

97. Pearson, R.D.; Symes, P.; Conboy, M.; Weiss, A.A.; Hewlett, E.L. Inhibition of monocyte oxidative responses by Bordetella pertussis adenylate cyclase toxin. J. Immunol. 1987, 139, 2749-2754.

98. Gordon, V.M.; Young, W.W., Jr.; Lechler, S.M.; Gray, M.C.; Leppla, S.H.; Hewlett, E.L. Adenylate cyclase toxins from Bacillus anthracis and Bordetella pertussis. Different processes for interaction with and entry into target cells. J. Biol. Chem. 1989, 264, 14792-14796.

99. Uhlen, P.; Laestadius, A.; Jahnukainen, T.; Söderblom, T.; Bäckhed, F.; Celsi, G.; Brismar, H.; Normark, S.; Aperia, A.; Richter-Dahlfors, A. Alpha-haemolysin of uropathogenic E. coli induces $\mathrm{Ca}^{2+}$ oscillations in renal epithelial cells. Nature 2000, 405, 694-697. [CrossRef]

100. Koschinski, A.; Repp, H.; Unver, B.; Dreyer, F.; Brockmeier, D.; Valeva, A.; Bhakdi, S.; Walev, I. Why Escherichia coli alpha-hemolysin induces calcium oscillations in mammalian cells-The pore is on its own. FASEB J. 2006, 20, 973-975. [CrossRef]

101. Skals, M.; Bjaelde, R.G.; Reinholdt, J.; Poulsen, K.; Vad, B.S.; Otzen, D.E.; Leipziger, J.; Praetorius, H.A. Bacterial RTX toxins allow acute ATP release from human erythrocytes directly through the toxin pore. J. Biol. Chem. 2014, 289, 19098-19109. [CrossRef]

102. Ludwig, A.; Benz, R.; Goebel, W. Oligomerization of Escherichia coli haemolysin (HlyA) is involved in pore formation. Mol. Gen. Genet. 1993, 241, 89-96. [CrossRef] [PubMed] 